NGUY CƠ RƠI VÀO BÃ̃Y THU NHẬP TRUNG BÌNH ĐỐI VỚI PHÁT TRIỂN KINH TẾ VIẸT NAM

\title{
VIETNAM AND THE THREAT OF FALLING INTO THE MIDDLE INCOME TRAP
}

\author{
Nguyễn Văn Luân \\ Trường Đại học Kinh tế - Luật, ĐHQG - HCM - Email: luannv@ uel.edu.vn \\ Ngô Văn Hải \\ Đại học Quốc gia TP. HCM
}

(Bài nhận ngày 02 tháng 02 năm 2015, hoàn chỉnh sửa chũa ngày 15 tháng 06 năm 2015)

\section{TÓM TẮT}

Bẫy thu nhập trung bình được đưa ra trong các nghiên cứu về trạng thái phát triển kinh tế của các quốc gia, là thuật ngũ dùng để chỉ tình trạng "mắc kẹt" của nhiều quốc gia đã đạt được mức thu nhập trung bình, trung bình thấp trong thời gian dài không thể trở thành nước có mức thu nhập cao. Năm 2008, Việt Nam đạt nguõng thu nhập trung bình thấp (1.052 USD/năm), thoát khỏi trạng thái các nuớc kém phát triển. Trong giai đoạn 2008 - 2014 tăng truởng kinh tế Việt Nam đạt mức bình quân 5,5 - 6\%/năm. Tuy nhiên, nền kinh tế đang ngày càng bộc lộ sự tăng truơong chậm, năng suất chưa cao, đồng vốn bỏ ra lớn nhung hiệu quả thấp, khả năng chuyển dịch co cấu kinh tế chậm... Theo lời cảnh báo của một số chuyên gia kinh tế, hiện nay nền kinh tế Việt Nam đang phải đối mặt với vấn đề sập "bẫy thu nhập trung binh".

Bài viết này trình bày một cách rõ nét về bẫy thu nhập trung bình, nguy co Việt Nam có thể rơi vào bẫy thu nhập trong phát triển kinh tế. Và đề xuất một số giải pháp để Việt Nam có thể tránh, vuoợt qua bẫy thu nhập trung bình và phát triển kinh tế bền vũng.

Tù khóa: Nguy co, bẫy thu nhập trung bình, phát triển kinh tế.

\begin{abstract}
The concept of middle income trap has been introduced in a plenty of research on a nation's economic development status which refers to the fact that many nations after attaining a certain income will get stuck at that level. Vietnam got rid of the list of least developed countries to join the lower middleincome countries with an annual GDP per capita of 1,052 USD in 2008. Vietnam enjoyed a steady GDP growth of $5.5-6 \%$ per year in the period between 2008 and 2014. However, the Vietnam's economy shows signs of slowdown, low productivity, low return on investment, and low economic transition. Vietnam is also warned to be under the threat of falling into the middle income trap. This paper aims to provide a clear picture of the middle income trap and the threat that Vietnam may fall into the middle income trap, thereby proposing some solutions for Vietnam to circumvent it and sustainably develop the economy.
\end{abstract}

Key words: Threat, middle income trap, economic development.

\section{Trang 68}




\section{GIỚI THIỆU}

Trạng thái bẫy thu nhập trung bình là một phạm trù của phát triển kinh tế. Đây là môt tình huống mang tính "tiến thoái lưỡng nan" trong xây dựng và thực hiện các chính sách phát triển kinh tế. Sự tồn tại của nó mang tính chất khách quan và có khả năng làm giảm hiệu quả những nỗ lực nhằm phát triển kinh tế theo hướng công nghiệp hóa, hiện đại hóa. Có không ít quốc gia gặp phải tình trạng này và là sự cảnh báo đối với các quốc gia khác trong điều hành và phát triển kinh tế.

Việt Nam trở thành quốc gia có thu nhập trung bình thấp và có những dấu hiệu rơi vào trạng thái bẫy thu nhập trung bình, có khả năng gây ra những tác động tiêu cực đến việc thực hiện các mục tiêu chiến lược phát triển kinh tế xã hội đến năm 2020 để Việt Nam cơ bản thành nước công nghiệp theo hướng hiện đại.

Cho đến nay, có nhiều nghiên cứu về tình trạng này ở nhiều quốc gia và các nghiên cứu đó là những nguồn tư liệu quan trọng để Việt Nam có thể tham chiếu. Tuy nhiên, các nghiên cứu về Việt Nam còn rất hạn chế và chưa nhận được sự quan tâm của các nhà hoạch định chính sách cũng như cộng đồng các doanh nghiệp và dân cư. Việc nhận thức bẫy thu nhập trung bình như là một căn cứ cảnh báo quan trọng đối với quá trình hoạch định chính sách và đầu tư phát triển kinh tế của Việt Nam đang đặt ra trong bối cảnh có nhiều thách thức đối với tiến trình công nghiệp hóa, hiện đại hóa và hội nhập quốc tế.

\section{CƠ SỞ LÝ THUYÊT VỂ BẪY THU NHẠP TRUNG BÌNH}

Khái niệm "bẫy thu nhập trung bình" được đưa ra trong các nghiên cứu về trạng thái phát triển kinh tế của các quốc gia. Những tác giả đưa ra khái niệm này là Gill và Kharas (2007) để chỉ ra tình trạng các nước đạt được mức thu nhập trung bình/người nhưng trong thời gian dài rơi vào tình trạng trì trệ, không chuyển sang nhóm các nước có thu nhập cao. Tiếp theo, xuất hiện các nghiên cứu của Yusuf, Ohno, Kumar và của $\mathrm{WB}$. Khái niệm này có những điểm khác nhất định so với lý thuyết vòng luẩn quẩn hay lý thuyết về các giai đoạn phát triển kinh tế của $\mathrm{W}$. Rostow được đưa ra vào năm 1960. Nếu nhìn nhận trong quá trình vận động của tư duy kinh tế thì có thể thấy khái niệm "bẫy thu nhập trung bình" chỉ là sự biểu hiện của trạng thái xuất hiện trong một khoảng thời gian nhất định trong tiến trình phát triển lâu dài của một quốc gia. Trong khi đó, việc nhận thức "bẫy thu nhập trung bình" lại ở một trạng thái cao hơn về thu nhập và không dẫn đến tình trạng nghèo khổ, nhưng việc thoát ra khỏi vùng đó đòi hỏi có những đột phá quan trọng. Lý thuyết của W. Rostow, nhận thức "bẫy thu nhập trung bình" chỉ xảy ra trong một giai đoạn nhất định, nghĩa là nó chỉ phản ánh một giai đoạn trong một khoản thời gian phát triển dài. Nói cách khác, nhận thức "bẫy thu nhập trung bình" nằm ở trình độ phát triển cao hơn của quốc gia so với vòng luẩn quẩn nhưng lại ngắn hạn hơn so với cách tiếp cận các giai đoạn phát triển kinh tế, vì trong đó có cả giai đoạn thu nhập thấp, thu nhập trung bình thấp, thu nhập trung bình cao và tiêu thụ hàng loạt hàng hóa tinh xảo - sự thể hiện trình độ phát triển cao của nền kinh tế có thu nhập cao.

Theo quan điểm của Kenichi Ohno (2009)[5], bẫy thu nhập trung bình là trạng thái phát triển kinh tế của một quốc gia khi một nước bị mắc kẹt tại mức thu nhập đạt được nhờ có nguồn tài nguyên và một số lợi thế nhất định mà không thể tiến lên để đạt mức cao nhất. Đây là trạng thái quốc gia chỉ dựa vào nguồn tài nguyên mà không có sự nỗ lực cần thiết. Bẫy này xảy ra tại các nước có mức thu nhập trung bình phụ thuộc đáng kể vào nguồn tài nguyên và lợi thế của nước đó. Nếu quốc gia có nhiều tài nguyên thì có khả năng đạt được thu nhập 
cao. Thực tế cho thấy, các nước giàu có về dầu mỏ là quốc gia có thu nhập cao nhưng cơ cấu kinh tế vẫn lạc hậu và do đó, dễ bị thụt lùi khi nguồn tài nguyên cạn kiệt. Cách giải thích này phản ánh khá cụ thể thực trạng và nguyên nhân của trạng thái "bẫy thu nhập trung bình", đó là "trần thủy tinh" khó nhận dạng cụ thể chuyển từ giai đoạn hấp thụ công nghệ sang sáng tạo công nghệ. Để vượt qua "trần thủy tinh" này cần tuyệt đối tránh tư duy "trung bình" trong phát triển. [6]

Theo quan điểm của Ngân hàng Phát triển Châu Á (ADB, 2011), một quốc gia rơi vào bẫy thu nhập trung bình là trường hợp quốc gia đó không có khả năng cạnh tranh với các nền kinh tế có tiền lương thấp, thu nhập thấp trong xuất khẩu hàng chế tạo và với các nền kinh tế phát triển dựa trên những thay đổi và đổi mới công nghệ, kỹ năng cao của người lao động. Các quốc gia đó không thể chuyển dịch đúng thời hạn từ mô hình tăng trưởng dựa vào nguồn lực, tiền lương và vồn sang tăng trưởng cao dựa vào năng suất các yếu tố tổng hợp - TFP.

Anna J. Arne J.N., José R.P (2012) [1] khi nghiên cứu so sánh kinh nghiệm tránh bẫy thu nhập trung bình của các nước/vùng lãnh thổ Đông Á và các nước Mỹ La tinh đã chỉ ra một số nền kinh tế mới công nghiệp hóa (NIEs) như Đài Loan, Hồng Kông, Hàn Quốc và Singapore thành công trong việc chuyển sang nhóm các nước có thu nhập cao trong khi các nước Mỹ Latinh vẫn ở trong trạng thái thu nhập trung bình. Nghiên cứu này chỉ ra NIEs Đông Á thành công nhờ theo đuổi tăng trưởng dựa vào xuất khẩu bằng cách tập trung đầu tư lớn và hiệu quả vào các ngành công nghiệp chiến lược (chẳng hạn Hàn Quốc có các ngành luyện thép, cơ khí và điện tử) tạo điều kiện để đa dạng hóa từng bước và chuyển sang phát triển các loại sản phẩm mới sử dụng công nghệ cao. Khi so sánh với các nước Mỹ La tinh, nghiên cứu chỉ ra thành công trong đa dạng hóa và tái cấu trúc cơ cấu xuất khẩu gắn với các chính sách hỗ trợ và tăng cường trong lĩnh vực giáo dục, cơ sở hạ tầng, sáng tạo và tiếp cận nguồn tài chính.

Một số học giả kinh tế và các nhà hoạch định chính gần đây đã nhấn mạnh sự mở rộng khái niệm bẫy thu nhập trung bình như là các rào cản phát triển, có thể xuất hiện cho bất kỳ quốc gia nào và ngăn chặn hay làm chậm lại quá trình thực hiện các mục tiêu phát triển. Việc mở rộng định nghĩa bẫy thu nhập trung bình sẽ góp phần giải thích cũng như làm cơ sở lý thuyết để cảnh báo các nguy cơ trì trệ kinh tế đối với ngay cả các nước mới chỉ vượt qua "bẫy nghèo", tức là đạt mức trung bình thấp như Việt Nam. Nguy cơ trì trệ sớm không chỉ do áp lực cạnh tranh sản xuất ngày càng tăng mạnh dưới tác động của làn sóng tự do hóa thương mại toàn cầu.

\section{NGUY CƠ SẬP "BẪY THU NHẬP TRUNG BÌNH" TRONG PHÁT TRIỂN KINH TẾ VIẸTT NAM}

Theo số liệu thống kê năm 2008 [11], Việt Nam đạt được mức thu nhập bình quân đầu người 1.052 USD và trở thành nước có thu nhập trung bình thấp (theo chuẩn của Ngân hàng Thế giớii) ${ }^{1}$. Kể từ thời điểm này, Việt Nam thoát khỏi tình trạng nước có thu nhập thấp. Tốc độ tăng trưởng kinh tế trung bình của Việt Nam trong giai đoạn 2008 - 2014 vào khoảng 5,5 - 6\%/ năm. Tuy nhiên, trong các nước ASEAN, Việt Nam vẫn thuộc nhóm bốn quốc gia (Campuchia, Lào, Mianma, Việt Nam) có thu nhập bình quân đầu người thấp nhất.

\footnotetext{
${ }^{1}$ Ngân hàng Thế giới phân loại các quốc gia thành viên thành các nhóm nước theo thu nhập bình quân đầu người. Ngưỡng thu nhập để phân nhóm quốc gia dựa trên số liệu năm 2012 như sau: Thu nhập thấp (dưới 1.035 USD/người); thu nhập trung bình thấp (1.036 - 4.085 USD/người); thu nhập trung bình cao (4.086 - 12.615 USD/người); thu nhập cao (từ 12.616 USD/người trở lên).
} 
Những kết quả đạt được trong năm 2014 của nền kinh tế Việt Nam đã có nhiều tín hiệu lạc quan. Tuy nhiên, trong năm qua vẫn còn một số lĩnh vực chưa đạt được kết quả theo mục tiêu, vẫn đang tồn tại những điểm nghẽn trong phát triển kinh tế. Tiến trình thực hiện tái cơ cấu nền kinh tế còn chậm; nợ công cao và cơ cấu chưa hợp lý; cân đối ngân sách nhà nước còn khó khăn. Năm 2014 nợ công của Việt Nam khoảng trên $60 \%$ GDP, nợ công đang tiến sát tới giới hạn an toàn theo quy định của Quốc hội là $65 \%$ GDP. Hoạt động sản xuất kinh doanh của các doanh nghiệp vẫn còn nhiều khó khăn, khả năng tiếp cận vốn còn nhiều hạn chế. Việc thực hiện ba đột phá chiến lược, trọng tâm là tạo lập môi trường cạnh tranh bình đẳng và cải cách hành chính dường như mới thể hiện được ở việc ban hành một số văn bản pháp quy có liên quan tới thể chế kinh tế thị trường. Kinh tế vĩ mô chưa thật sự vững chắc, còn tiềm ẩn nhiều yếu tố gây bất ổn dài hạn của nền kinh tế. Tốc độ tăng trưởng GDP năm 2014 cao hơn so với 3 năm trước đây; thế nhưng tăng trưởng còn ở dưới mức tiềm năng và chưa có chuyển biến một cách tích cực về chuyển đổi mô hình tăng trưởng theo hướng bền vững.

Sau 7 năm đạt được mức thu nhập trung bình thấp, trong thời kỳ này tăng trưởng kinh tế của Việt Nam chậm lại, nguy cơ vướng "bẫy thu nhập trung bình" của Việt Nam không còn là một nguy cơ xa xôi, mà đã có những biểu hiện hiện hữu và rất đa dạng. Những triệu chứng này có thể nhìn nhận thông qua các khía cạnh sau đây:

Thư nhất, tốc độ tăng trưởng kinh tế bình quân của Việt Nam trong 7 năm qua vào khoảng $5,5-6 \%$ chưa đáp ứng yêu cầu cần thiết để thúc đẩy phát triển kinh tế nhanh và bền vững (Biểu đồ 1).

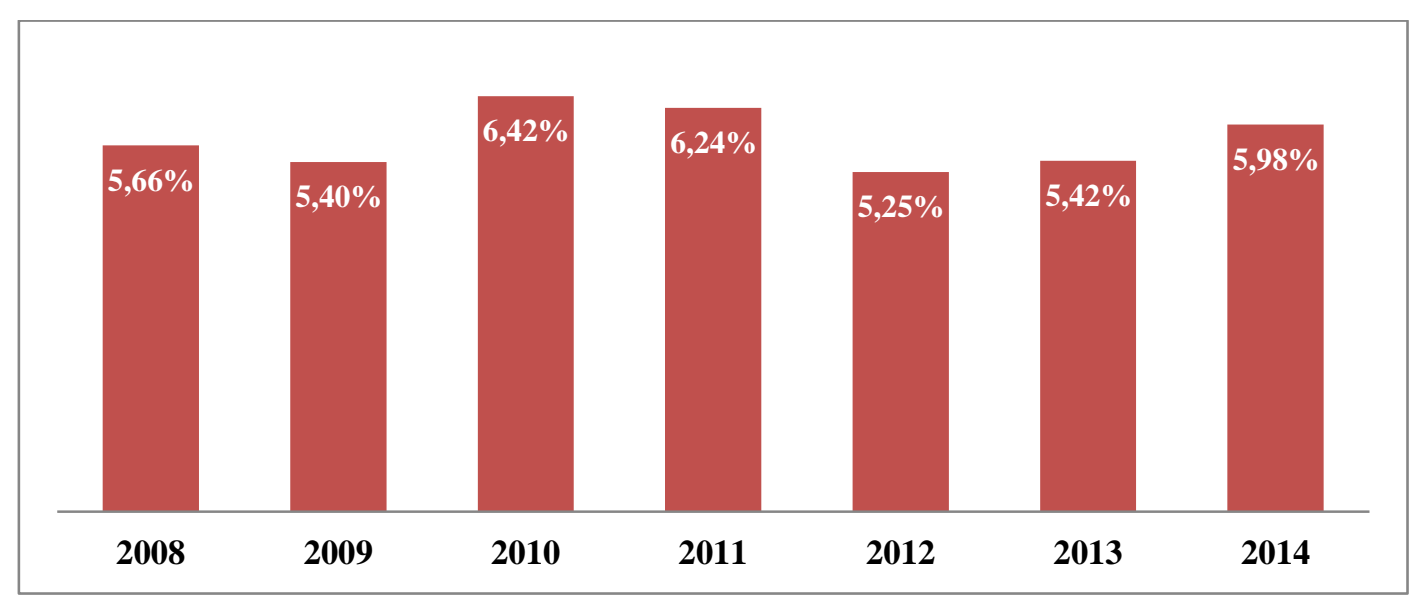

Biểu đồ 1. Tốc độ tăng GDP qua các năm

Nguồn: Tổng cuc Thống kê, Niên giám Thống kê năm 2010, 2014

Việt Nam là một nền kinh tế với tiềm năng phát triển cao, với mức tăng trưởng bình quân 5 - $6 \%$ cũng được xem như là sự trì trệ trong phát triển kinh tế.
Tăng trưởng kinh tế của Việt Nam chủ yếu dựa trên gia tăng đầu vào, bao gồm cả việc mở rộng tín dụng. Mặc dù nguồn cung lao động tăng, nhưng chất lượng nguồn nhân lực không được cải thiện. Đầu tư đóng góp tương đối cao 
trong tăng trưởng GDP của Việt Nam. Tổng mức đầu tư so với GDP đã tăng đáng kể từ năm 2000. Tuy nhiên, hiệu quả của mức đầu tư cao chưa tạo ra được hiệu ứng số nhân đối với sản lượng trong nền kinh tế. So sánh chỉ số ICOR của Việt Nam so với các nước Đông Á lân cận (xem David và cộng sự, 2008). Gần đây, tốc độ tăng trưởng phụ thuộc vào đầu tư và xuất khẩu trong khi nền kinh tế đang đối mặt với thâm hụt kép.

Một hệ quả trực tiếp của việc áp dụng chiến lược tăng trưởng dựa trên đầu tư là gia tăng khoảng cách đầu tư và tiết kiệm. Tỷ lệ tiết kiệm trong nước của Việt Nam là vừa phải, khoảng $30 \%$. Tỷ lệ đầu tư phát triển khoảng 40\% GDP; khoảng cách này làm cho tài khoản vãng lai rơi vào tình trạng thâm hụt. Ngoài ra, Chính phủ cũng đang chịu gánh nặng thâm hụt ngân sách hàng năm đều tăng lên.

Từ một nền kinh tế đang phát triển ở trình độ thấp, tốc độ tăng trưởng kinh tế của Việt Nam trong giai đoạn này đạt được tương đối cao so với một số quốc gia khác trong khu vực và trên Thế giới, nhưng sự tăng trưởng này lại thiếu ổn định, khó có thể tạo được tiền đề vững chắc để "cất cánh" hay để thoát ra khỏi "bẫy thu nhập trung bình". Mặc dù, mục tiêu tăng trưởng kinh tế bình quân 5 năm tới (2016 2020) đạt 6,5 - 7\%/năm.

Thực tiễn và kinh nghiệm của các nền kinh tế mới công nghiệp hóa nhanh chóng vượt qua bẫy thu nhập trung bình đều có tốc độ tăng trưởng bình quân trong giai đoạn "cất cánh" từ 9 - 10\%/năm, thậm chí còn cao hơn.

Thư hai, mức thu nhập bình quân đầu người đạt được trong những năm qua còn ở mức thấp. Việt Nam mới trở thành nước có thu nhập trung bình thấp cho nên khả năng để tiếp cận ngưỡng của mức thu nhập trung bình hay ngưỡng thu nhập trung bình cao còn khá dài. Khoảng thời gian này có thể kéo dài không dưới 10 năm với kịch bản lạc quan là tốc độ tăng trưởng kinh tế phải đạt được bình quân từ 8 - 9\%/năm, khi không có các cuộc khủng hoảng kinh tế hay suy thoái kinh tế đe dọa làm suy giảm hoặc làm gián đoạn tốc độ tăng trưởng này. (Biểu đồ 2).

Đơn vị: USD/người

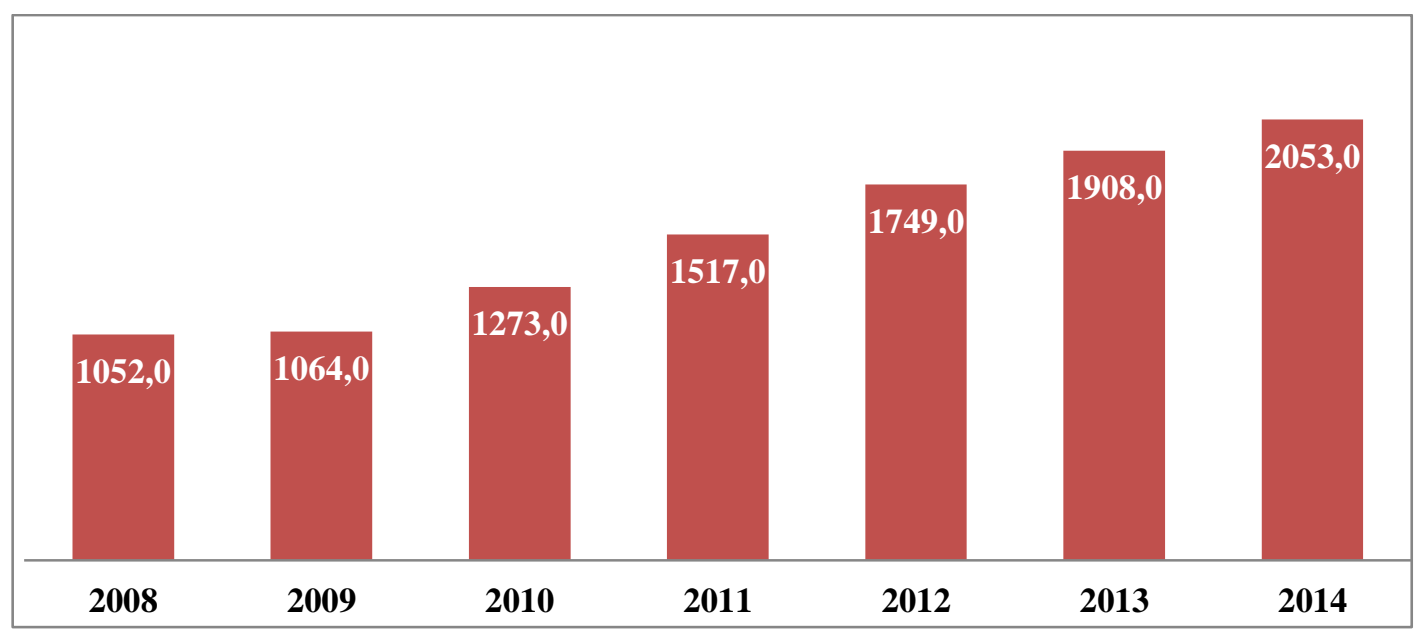

Biểu đồ 2. GDP bình quân đầu người tính bằng USD theo tỷ giá hối đoái

Nguồn: Tổng cục Thống kê, Niên giám Thống kê năm 2010, 2014

Trang 72 
Thú $b a$, hiệu quả đầu tư, đặc biệt đầu tư công không cao. Nếu đánh giá hiệu quả này thông qua chỉ số ICOR có thể thấy trong giai đoạn 2006 - 2010, ICOR của khu vực Nhà nước, tư nhân và đầu tư nước ngoài lần lượt là: 10,2 - 5 - 9,7; giai đoạn 2011 - 2014 là: 6,2 3,4 - 5,1 [11,13]. Đầu tư công của Việt Nam kém hiệu quả gây ra tình trạng thua lỗ nặng nề của các doanh nghiệp nhà nước. Đặc biệt là các Tập đoàn kinh tế nhà nước. Tình trạng thâm hụt ngân sách, mở rộng tiền tệ gây ra tình trạng lạm phát hoặc tạo ra cơ hội để xuất hiện nhiều thách thức hơn đối với quá trình phát triển kinh tế. Điều này cho thấy hiệu quả đầu tư thấp khó có thể tạo đủ tiền đề cơ bản để tăng trưởng ổn định nếu chưa nói là làm suy giảm chất lượng tăng trưởng, lãng phí nguồn lực và làm lệch lạc các nỗ lực từ phía Nhà nước và doanh nghiệp. Hiệu quả đầu tư không cao còn làm giảm mức độ tiết kiệm cũng như khả năng huy động nguồn lực có hiệu quả. Nhìn tổng thể, mô hình tăng trưởng kinh tế của Việt Nam trong thời gian qua là tăng trưởng theo chiều rộng, chưa có những nền tảng cơ bản để phát triển theo chiều sâu cho nên khả năng vượt qua bẫy thu nhập trung bình là hết sức khó khăn.

Thư $t u$, nền kinh tế phụ thuộc đáng kể vào khu vực có vốn đầu tư nước ngoài, vì khu vực này còn được coi là tận dụng được nhiều nhất nguồn lực bên ngoài để đưa Việt Nam thoát khỏi vòng luẩn quẩn. Việc giảm thiểu tác động vượt trội của khu vực này chưa có giải pháp thích hợp. Theo Tổng cục thống kê, tỷ lệ đóng góp vào GDP của khu vực có vốn đầu tư nước ngoài có xu hướng tăng lên, mức trung bình từ 14,6\% trong thời kỳ 2001 - 2005 lên 19,55 \% GDP năm 2013. Đối với kim ngạch xuất khẩu, tỷ lệ đóng góp này trong những năm gần đây có xu hướng tăng nhanh. Năm 2014, kim ngạch xuất khẩu của Việt Nam đạt trên 150 tỷ USD, trong đó khu vực có vốn đầu tư nước ngoài đạt 101,6 tỷ USD, đóng góp khoảng 2/3. Lợi thế của khu vực này là sản xuất hàng chế tạo, đặc biệt là linh kiện điện tử và điện thoại có khả năng cạnh tranh cao mà các doanh nghiệp trong nước không thể sản xuất được do thiếu năng lực làm chủ công nghệ trung bình và công nghệ cao. Đây là kết quả của tư tưởng dựa vào đầu tư nước ngoài mà thiếu đi chiến lược tiếp nhận hợp lý, đặc biệt là chiến lược đổi mới công nghệ theo hướng tăng khả năng cạnh tranh bền vững và lâu dài cả trên thị trường trong nước và thị trường thế giới. Có thể nói, sự phụ thuộc quá lớn vào nhà đầu tư nước ngoài có thể là một trong những nguy cơ làm cho đất nước rơi vào trạng thái bẫy thu nhập trung bình vì sự thao túng đáng kể của nhà đầu tư nước ngoài theo hướng điều chỉnh chính sách có lợi cho các nhà đầu tư nước ngoài.

Thứ năm, các yếu tố khác có khả năng chi phối đến sập bẫy thu nhập trung bình là cơ cấu kinh tế chuyển dịch chậm, tỷ trọng ngành nông nghiệp trong GDP hàng năm có giảm xuống, nhưng tổng giá trị gia tăng trong sản xuất nông nghiệp tăng chậm. Năm 2014, tỷ trọng ngành nông, lâm - thủy sản giảm xuống còn $18,12 \%$, tỷ trọng ngành công nghiệp và dịch vụ tăng lên chiếm $81,88 \%$; song chủ yếu là công nghiệp có giá trị gia tăng thấp và phụ thuộc đáng kể vào đầu tư nước ngoài. Đồng thời, chính sách tiền lương tối thiểu thấp làm giảm động lực phấn đấu của người lao động, vừa tạo điều kiện để nhà đầu tư nước ngoài triệt để lợi dụng, thậm chí "bóc lột" nguồn lao động giá rẻ để tăng khả năng cạnh tranh toàn cầu, vừa tạo điều kiện cho tình trạng "chảy máu chất xám" từ khu vực tiền lương thấp sang khu vực tiền lương cao, đặc biệt khu vực có vốn đầu tư nước ngoài.

Việt Nam đang phải đối mặt với sự không chắc chắn trong các nỗ lực nhằm duy trì tốc độ tăng trưởng cao của sự phát triển kinh tế trong thời gian dài. Các doanh nghiệp trong nước vẫn thiếu năng lực cạnh tranh, các chính sách và thể chế vẫn còn yếu so với tiêu chuẩn khu vực 
Đông Á (Ohno, 2009b) [5]. Nền kinh tế vẫn còn phụ thuộc vào các ngành công nghiệp khai thác tài nguyên hoặc các ngành thâm dụng lao động giá rẻ. Chuyển dịch cơ cấu kinh tế theo hướng công nghệ cao rất chậm chạp và vẫn bị chi phối bởi các ngành công nghiệp công nghệ thấp. Các doanh nghiệp nhà nước chưa đóng vai trò đầu tàu trong hoạt động sản xuất kinh doanh và đổi mới công nghệ; trong khi khu vực kinh tế tư nhân vẫn còn nhiều hạn chế, chưa trở thành động lực cho sự phát triển kinh tế. Việt Nam đang chỉ ở giai đoạn đầu tư của công nghiệp hóa và hiện đại hóa. Sản xuất vẫn chủ yếu chịu sự chi phối của các doanh nghiệp nước ngoài.

Việt Nam đang phải đối mặt với một số vấn đề có tính dễ bị tổn thương của nền kinh tế. Vào cuối năm 2007 và đầu năm 2008, Việt Nam đã phải đối mặt với kinh tế quá nóng do tăng trưởng tín dụng rất lớn và dòng vốn đầu tư khổng lồ. Năm 2008, lần đầu tiên, Chính phủ công khai thừa nhận sự đánh đổi giữa tăng trưởng kinh tế và ổn định kinh tế vĩ mô. Việt Nam đã mở rộng tín dụng rất lớn trong năm 2007, cùng với giá năng lượng và lương thực thế giới tăng, đã gây ra áp lực lạm phát. Ngoài ra, để ứng phó với các dòng vốn lớn (cả FDI và đầu tư gián tiếp), Chính phủ chưa có được những chính sách phù hợp nhằm hấp thụ dòng vốn này trong khi duy trì một tỷ giá hối đoái cố định. Điều này đã buộc Chính phủ phải thay đổi các ưu tiên từ tăng trưởng sang ổn định kinh tế vào năm 2008 với các biện pháp cũng như chính sách thắt chặt tiền tệ và cắt giảm chi tiêu công. Chính sách này cũng đã phát huy tác dụng làm giảm lạm phát, kìm hãm thị trường nhà ở và bong bóng bất động sản.

Tăng trưởng kinh tế gần đây còn bắt nguồn từ các chính sách mở cửa kinh tế, trong đó trọng tậm là tự do hóa thương mại. Từ khi gia nhập chính thức Tổ chức thương mại thế giới (WTO) vào năm 2007, nền kinh tế Việt Nam đã có những thay đổi to lớn. Mặc dù nguồn FDI dồi dào và có được những công nghệ mới, chi phí lao động rẻ và tài nguyên thiên nhiên phong phú, nhưng sản phẩm và dịch vụ của Việt Nam vẫn yếu trong cạnh tranh quốc tế do chi phí giao dịch cao. Theo các nhà nghiên cứu và hoạch định chính sách ở Việt Nam, cải cách kinh tế dựa vào lý thuyết tự do hóa thương mại truyền thống dường như không còn dư địa vì hầu hết hàng rào thuế quan và phi thuế quan đã được loại bỏ.

Cuộc khủng hoảng kinh tế thế giới năm 2008 - 2009 giống như một chất xúc tác mạnh làm bộc lộ những bất cập của nền kinh tế Việt Nam trong môi trường kinh tế toàn cầu. Qua những năm khó khăn, có thể thấy rõ một sự mất cân bằng của nền kinh tế như sau:

Một là, mô hình tăng trưởng kinh tế tạo nên những mất cân đối vĩ mô trầm trọng và khiến việc cải thiện là khó khăn. Tâm điểm của các cân đối vĩ mô là mất cân đối giữa tổng tiết kiệm và tổng đầu tư của nền kinh tế (tổng tiết kiệm chiếm khoảng 30\% GDP) trong khi đó tổng đầu tư (khoảng $40 \%$ GDP), tạo ra khoảng cách giữa tiết kiệm và đầu tư khoảng $10 \%$ GDP. Sự mất cân đối này bắt nguồn từ mô hình tăng trưởng dựa trên mở rộng đầu tư, trong đó đầu tư công chiếm tỷ trọng lớn (khoảng $50 \%$ tổng đầu tư toàn xã hội). Trong một nền kinh tế đang phát triển như Việt Nam, đầu tư công vào các công trình hạ tầng xã hội và công nghiệp có ý nghĩa quan trọng, làm tiền đề cho tăng trưởng kinh tế trong toàn bộ các khu vực còn lại khác. Những nước có nền kinh tế với mức thu nhập trung bình như Ấn Độ hay Indonexia cảm thấy rất khó tìm được sự đồng thuận trong việc phân bổ nguồn lực lớn cho đầu tư công, do đó, cơ sở hạ tầng ở các nước này luôn là một nút thắt cổ chai cho phát triển. Trái lại, các nước như Việt Nam hay Trung Quốc có lợi thế lớn trong việc huy động nguồn lực xã hội cho các dự án đầu tư công lớn. Tuy nhiên, điều đáng tiếc là ở Việt 
Nam, chất lượng đầu tư công giảm đi nhanh chóng. Điều này vừa khiến tình trạng lãng phí nguồn nhân lực và bất bình đẳng tăng lên, vừa tạo ra sự mất cân đối vĩ mô của nền kinh tế. Sự mất cân đối này, một mặt, thể hiện qua thâm hụt ngân sách tăng cao, mặt khác, dẫn tới thâm hụt thương mại triền miên. Thâm hụt ngân sách cao ảnh hưởng tiêu cực đến thị trường ngoại hối, đe dọa giảm sút giá trị của đồng tiền Việt Nam.

Hai là, động năng của khu vực doanh nghiệp giảm sút. Thời kỳ kinh tế khó khăn khiến các doanh nghiệp trong một nền kinh tế có độ mở lớn như Việt Nam (tổng kim ngạch xuất khẩu vượt qua 170\% GDP) phải chịu đựng những rủi ro trực tiếp từ sự suy thoái của thị trường toàn cầu. Trong khi đó, bất ổn kinh tế vĩ mô trong nước càng làm tăng mức độ rủi ro của hoạt động đầu tư và kinh doanh sản xuất trong nước. Lạm phát cao làm lu mờ các tín hiệu trong tương lai của công việc kinh doanh, đồng thời lãi suất cao trong thời gian dài làm thoái lui các dự án đầu tư mở rộng sản xuất. Trong khi đó, khu vực kinh tế nhà nước vẫn hiện diện như một khu vực chi phối nền kinh tế (tỷ trọng đóng góp vào GDP là $35 \%$ so với mức $15 \%$ ở Trung Quốc). Khu vực này dù ít hay nhiều vẫn có những lợi thế trong thời kỳ chịu sự tác động của khủng hoảng kinh tế toàn cầu. Thêm vào đó, đa số các doanh nghiệp nhà nước có vị thế độc quyền, nên có nhiều khả năng tăng giá bán để bù đắp lạm phát hơn so với doanh nghiệp vừa và nhỏ của khu vực tư nhân. Khu vực kinh tế tư nhân lần đầu tiên đối diện với sự tác động của khủng hoảng kinh tế toàn cầu đã phải thu hẹp, đóng cửa và phá sản một lượng lớn doanh nghiệp nhỏ và vừa trong nền kinh tế. Đây là tín hiệu đáng lo ngại đối với nền kinh tế, trong khi chúng ta đang khuyến khích, tạo thuận lợi cho kinh tế tư nhân phát triển ở hầu hết các ngành và lĩnh vực để khu vực kinh tế tư nhân trở thành động lực cho sự phát triển kinh tế.
$B a$ là, hệ thống tài chính và các thị trường tài sản tích tụ nhiều rủi ro và đang bộc lộ rõ những yếu kém. Và là một trong những nguyên nhân làm tăng thêm bất ổn kinh tế vĩ mô. Khi thị trường chứng khoán đi vào trạng thái bong bóng sau khi Việt Nam gia nhập Tổ chức Thương mại thế giới (WTO) vào năm 2007 và tiếp đó là sự bùng nổ của hệ thống ngân hàng thương mại, nhiều người còn hoài nghi về những rủi to do sự tăng trưởng quá nóng gây ra. Tuy nhiên, bong bóng lớn thực sự nằm trong thị trường bất động sản, nơi có chu kỳ tăng trưởng dài hơn rất nhiều. Những khó khăn trong và ngoài nước đã cùng làm bong bóng bất động sản và chứng khoán xì hơi, tạo ra những khoản nợ xấu đe dọa sự bền vững của toàn bộ hệ thống ngân hàng. Ngay cả trong hệ thống ngân hàng, chính sách trần lãi suất huy động trong những năm qua đã tự nó tạo ra một cuộc tái cấu trúc ngược, trong đó trao thêm càng nhiều đặc quyền và sức mạnh cho các ngân hàng quốc doanh, đồng thời làm suy yếu các ngân hàng thuộc khối tư nhân.

Bốn là, xét trên toàn bộ nền kinh tế, tính sáng tạo, nghiên cứu và phát triển $(R \& D)$ trong sản xuất kinh doanh hầu như chưa xuất hiện, khiến thị trường lệ thuộc nhiều vào nước ngoài, đặc biệt đối với hàng máy móc và nguyên vật liệu phục vụ sản xuất. Điều này lý giải tình trạng nhập siêu trầm trọng từ Trung Quốc và gần đây là Hàn Quốc. Trong khi đa số các nước Đông Nam Á đều có xuất siêu vào Trung Quốc và nhờ đó được lợi rất nhiều từ sự trỗi dậy của nền kinh tế lớn nhất Châu Á, thì Việt Nam dường như bị đẩy vào một trạng thái rất bị động. Sự lệ thuộc vào nhập khẩu nguyên liệu và phương tiện sản xuất, tự nó tạo ra rào cản cho việc giảm giá đồng tiền Việt Nam. Do đó, dưới chế độ tỷ giá luôn có khuynh hướng tăng lên trong suốt một thập kỷ vừa qua, sản xuất nội địa Việt Nam đang ngày càng mất dần tính cạnh tranh ngay trong nội địa và khả năng đầu 
tư cho quá trình sản xuất để có được giá trị gia tăng cao, mang tính sáng tạo nhiều hơn của các doanh nghiệp trong nước (kể cả khu vực có vốn đầu tư nước ngoài) ngày càng giảm sút.

\section{GIẢI PHÁP VƯợT QUA BÃ̃Y THU NHẬP TRUNG BÌNH CỦA VIỆT NAM}

Vượt qua "bẫy thu nhập trung bình" của Việt Nam là một thách thức khách quan xuất phát từ quan hệ nội tại trong nền kinh tế và bối cảnh tham gia hội nhập kinh tế toàn cầu. Những cơ hội và thách thức bên trong và bên ngoài đang là tiền đề, điều kiện và là những lực cản đối với sự phát triển kinh tế của Việt Nam. Việc nhận thức đúng và đầy đủ "bẫy thu nhập trung bình" tạo điều kiện hiểu rõ hơn trạng thái và xu hướng vận hành để thích nghi với tiến trình phát triển kinh tế ở Việt Nam trong giai đoạn 2016 đến 2020 và những năm tiếp theo. Trong thời kỳ này, khả năng rơi vào bẫy thu nhập trung bình được coi là một trong những thách thức rất lớn đối với sự phát triển kinh tế của Việt Nam. Đây là khoảng thời gian cần được cải thiện một cách hiệu quả đầu tư và áp dụng một cách đồng bộ các giải pháp có tính đột phá để vượt qua bẫy thu nhập trung bình. Các giải pháp cơ bản để Việt Nam có thể vượt qua bẫy thu nhập trung bình trong thời kỳ tiếp tục đẩy mạnh công nghiệp hóa, hiện đại hóa và hội nhập quốc tế bao gồm:

Thứ nhất, chuyển đổi triệt để mô hình tăng trưởng kinh tế từ chiều rộng sang chiều sâu và coi trọng áp dụng rộng rãi các tiến bộ khoa học công nghệ trong các ngành công nghiệp có thế mạnh và lợi thế so sánh, lợi thế cạnh tranh để tăng khả năng sử dụng hiệu quả các nguồn lực, tối ưu hóa quy mô và tối đa hóa năng suất, hạn chế được tính quy luật của năng suất biên giảm dần, hướng tới trạng thái tính kinh tế nhờ quy mô qua năng suất biên tăng dần. Việc chuyển đổi mô hình cần bắt đầu từ việc quy hoạch phát triển các ngành, vùng hay loại sản phẩm, dịch vụ theo hướng đảm bảo tính khoa học và thực tiễn cao. Các ngành sử dụng thế mạnh nền nông nghiệp, nguồn tài nguyên biển, nguồn tài nguyên sẵn có cần được coi trọng đầu tư và trở thành nghành kinh tế mũi nhọn của Việt Nam trong tương lai.

Thư hai, thực hiện quyết liệt ba đột phá chiến lược về hoàn thiện thể chế kinh tế thị trường định hướng xã hội chủ nghĩa, nâng cấp cơ sở hạ tầng và phát triển nguồn nhân lực chất lượng cao để tạo chuyển biến cơ bản về tiền đề phát triển kinh tế nhằm chuyển dịch nhanh chóng từ trạng thái thu nhập trung bình sang trạng thái thu nhập cao. Việc thực hiện các đột phá này gắn với chuyển đổi mô hình tăng trưởng theo chiều sâu và tái cấu trúc nền kinh tế.

Thư $b a$, cần khai thác các thế mạnh hiện có của nền kinh tế Việt Nam, trong đó có lợi thế về cơ cấu dân số vàng với khoảng $70 \%$ số dân ở độ tuổi lao động trẻ nhằm tăng tốc độ tăng trưởng trung bình ở mức 8 - 9\% liên tục trong vòng 10 - 15 năm. Điều này đòi hỏi đào tạo nguồn nhân lực chất lượng cao, có khả năng sáng tạo lớn và đổi mới căn bản giáo dục - đào tạo nhằm tạo nền tảng về nguồn nhân lực dài hạn vượt qua bẫy thu nhập trung bình có hiệu quả. Ở đây, sự sáng tạo, đặc biệt là sự sáng tạo mang bản chất thương mại, nghĩa là sự sáng tạo nhằm tạo lợi nhuận tối đa, gần như là yếu tố cốt lõi của quá trình vượt qua bẫy thu nhập trung bình. Thực chất đây là quá trình tạo ra những loại công nghệ mới hay công nghệ cao, sáng tạo ra các sản phẩm có khả năng thay đổi cơ bản trạng thái nhu cầu của thị trường, tăng năng suất và cải thiện năng lực cạnh tranh để tăng giá trị mới hoặc ít ra cũng tiếp nhận, làm chủ được công nghệ cao, sáng tạo ra các sản phẩm có khả năng thay đổi cơ bản trạng thái nhu cầu của thị trường, tăng năng suất và cải thiện năng lực cạnh tranh để tăng giá trị mới hoặc ít ra cũng tiếp nhận, làm chủ công nghệ cao của Thế giới vào quá trình sản xuất. Những

\section{Trang 76}


thế mạnh nhiều mặt của nền kinh tế Việt Nam về nguồn lực và đổi mới chính sách cho thấy Việt Nam hoàn toàn có khả năng để vượt qua bẫy thu nhập trung bình có hiệu quả.

Thư $t u$, cần chủ động, tích cực hội nhập kinh tế quốc tế để kết hợp hiệu quả ngoại lực và nội lực. Việc chủ động, tích cực đẩy mạnh các cuộc đàm phán quốc tế, ký kết các hiệp định song phương và đa phương là cần thiết và cần được coi là định hướng chiến lược cơ bản trong hội nhập. Đồng thời, tích cực khai thác có hiệu quả nguồn nhân lực bên ngoài bao gồm nguồn vốn đầu tư, công nghệ, kiến thức và kỹ năng quản lý để tạo ra những thay đổi căn bản trạng thái vận hành nền kinh tế trên cơ sở các mô hình thành công trong công nghiệp hóa. Các nền kinh tế vượt qua được bẫy thu nhập trung bình như Hàn Quốc, Đài Loan, Singapore,... cho thấy yếu tố cốt lõi là sự sáng tạo được phát huy tối đa trên cơ sở thể chế ủng hộ triệt để sự sáng tạo của các cá nhân, các doanh nghiệp. Giải pháp này đòi hỏi tận dụng đến mức cao nhất các cơ hội do chủ động, tích cực hội nhập quốc tế mang lại. Bên cạnh đó, cần có sự thay đổi về tầm nhìn và cách tiếp cận trong phát triển kinh tế lấy động lực và thị trường toàn cầu làm căn cứ chủ yếu trong hoạch định chính sách và chiến lược phát triển. Đây là quá trình nhận thức không có giới hạn các nguồn lực phát triển, đặc biệt là nguồn vốn, công nghệ, thị trường và tri thức để loại bỏ những lực cản níu kéo khả năng rơi vào "bẫy thu nhập trung bình" nhằm đưa đất nước thoát khỏi bẫy thu nhập trung bình, trở thành nước công nghiệp theo hướng hiện đại vào năm 2020.

Để vượt qua được "bẫy thu nhập trung bình”, Việt Nam vẫn cần phải thực hiện chiến lược tăng trưởng nhanh trong thời gian tới gắn với chất lượng, hiệu quả và khả năng duy trì lâu dài. Chú trọng tạo dựng và duy trì cấu trúc tăng trưởng hợp lý, ngày càng thể hiện rõ mô hình tăng trưởng theo chiều sâu. Chú trọng việc nâng cao hiệu quả đầu tư, hiệu quả sử dụng lao động, nâng cao chất lượng nguồn nhân lực, phát triển khoa học công nghệ gắn liền với đổi mới tư duy và sáng tạo, tạo tiền đề đột phá về năng suất lao động. Tiếp tục hoàn thiện thể chế kinh tế thị trường định hướng xã hội chủ nghĩa và vận hành một cách thông suốt, có hiệu quả; tạo động lực thúc đẩy nền kinh tế phát triển nhanh và bền vững.

\section{KẾT LUẬN}

Việc nhận thức và tư duy về "bẫy thu nhập trung bình" có vai trò quan trọng trong đánh giá đúng trạng thái kinh tế Việt Nam. Cách tiếp cận "bẫy thu nhập trung bình" có thể có sự khác nhau đối với các nền kinh tế khác nhau song vẫn có những điểm chung nhất định như: rất khó khăn để chuyển lên trạng thái thu nhập cao, năng lực thiếu đồng bộ... Bên cạnh đó, còn có những tác động từ các kết quả tạo ra thiếu chiều sâu, giá trị gia tăng thấp mà vẫn được thị trường chấp nhận và chịu sự cạnh tranh gay gắt từ bên ngoài .

Việt Nam có khả năng rơi vào bẫy thu nhập trung bình cho nên cần có các giải pháp để có thể tránh và vượt qua bẫy thu nhập trung bình thông qua việc sử dụng hiệu quả các nguồn lực, coi trọng chuyển đổi mô hình tăng trưởng kinh tế và tái cấu trúc nền kinh tế, thực hiện một cách có hiệu quả ba mũi đột phá chiến lược.

Việt Nam có thể tránh được bẫy thu nhập trung bình hay không và có thể rút ngắn được con đường bứt phá hơn nữa hay không? Câu trả lời hoàn toàn phụ thuộc vào việc điều hành và các chính sách kinh tế vĩ mô của Chính phủ. Mặc dù nền kinh tế đang xuất hiện tính dễ tổn thương nhưng xét về tổng thể, nền kinh tế Việt Nam vẫn hội đủ các điều kiện để vượt qua bẫy thu nhập trung bình. Vấn đề là cần phải có một chiến lược bứt phá để nhanh chóng trở thành nhóm các nước có thu nhập cao thông qua tăng 
trưởng cao và bền vững. Chiến lược này khác hẳn với chiến lược phát triển thoát ra khỏi các nước kém phát triển. Sự khác biệt cơ bản là ở tư duy, quan điểm, thể chế và chính sách cho phát triển kinh tế.

\section{TÀI LIÊU THAM KHẢO}

[1]. Anna Jankowska, Arne J. Nagengast and Jose Ramon Parea: The middle - income Trap: Comparing Asian and Latin American Experiences, Policy Insight No.96, May 2012 www.oecd.org/dev/insight.

[2]. Bùi Tất Thắng, Vấn đề "bẫy thu nhập trung bình" đối với phát triển kinh tế ở Việt Nam (2014).

[3]. Đảng cộng sản Việt Nam, Văn kiện Đại hội Đại biểu toàn quốc lần thứ XI, Nxb. Chính trị quốc gia - sự thật, Hà Nội (2011).

[4]. Đỗ Thị Đông, Tránh bẫy thu nhập trung bình: Thực trạng các nước trong khu vực Châu Á và bài học tham khảo đối với Việt Nam. Kỷ yếu hội thảo "Các vấn đề lý luận cơ bản về nước công nghiệp hiện đại, nuớc công nghiệp hiện đại theo định huoóng xã hội chủ nghĩa và kinh nghiệm quốc tế về phát triển nuơóc công nghiệp hiện đại. (Đề tài KX 04.07/11 - 15) (2013).

[5]. Kenichi Ohno, Bẫy thu nhập trung bình tại Việt Nam: Thục trạng và giải pháp (2014). http:www.grips.ac.jp/vietnam/koarchives/doc/VS30_MIT_NEU.pdf.

[6]. Kenichi Ohno: Vuoọt qua bẫy thu nhập trung binh: Đổi mới chính sách công nghiệp Việt Nam (2010).

[7]. Ngân hàng thế giới (WB), Các muc tiêu tác nghiệp hàng năm (2012).

[8]. Nguyễn Đức Thành, Lê Kim Sa, "Bẫy thu nhập trung bình" - Lý thuyết, thực tiễn và hàm ý với Việt Nam (2014).

[9]. Nguyễn Thường Lạng, Một số vấn đề lý luận về "bẫy thu nhập trung binh" và liên hệ với Việt Nam (2014).

[10]. Tổng cục thống kê: Niên giám thống kê 2010, Nxb Thống kê (2010).

[11]. Tổng cục thống kê: Niên giám thống kê 2013, Nxb Thống kê (2013).

[12]. Tổng cục thống kê: Số liệu thống kê 2014 (2014).

[13]. Trần Thọ Đạt, Thoát bẫy thu nhập trung bình: Bài học kinh nghiệm của các nuớc thành công và hàm ý cho Việt Nam (2014). 